\title{
PERFECT, MIDDLE VOICE AND INDOEUROPEAN VERBAL ENDINGS
}

A review of new theories on the origin of perfect and middle voice. The author criticizes theories explaining the origin of perfect from nominal forms and attributing to thematic vowel an original value of middle voice. On the contrary, perfect as well as middle voice originated from forms older than these cathegories and independent from them. This is precisely the case of the thematic vowel. The author believes this is only a part of the general development of Indoeuropean verb which stems from a monothematic system toward a polythematic one. Actually, perfect and middle voice belong to the oldest stage in this process. This is a further step on the base of ideas exposed by the author in his Evolución y estructura del verbo indoeuropeo and other works.

\section{New discoveries in this field}

The impact caused among scholars of IE Linguistics by the discovery of the clase relationship existing between the middle endings of Hitt. $-b a,-t a,-a$ (and 3rd. pl. $-r$ ) and those of the IE perfect, is only too wellknown. This discovery was made simultaneously and independently by Chr. Stang (1932) and J. Kuryłowicz (1932). On the other hand, in view of the fact that the middle endings in question are in turn close to the middle endings of IE in general, this discovery opened up new perspectives for the research of the origins of both the middle voice and the perfect.

I am not going to set down here the history of the different doctrines which have followed one another on this matter. I have already done this in two former publications (Adrados 1963: $100 \mathrm{ff}$. and 1972), in which I criticized the first two interpretations which appeared, namely that the middle voice came from the perfect and that the perfect came from the middle voice. I put forward a new interpretation which I still consider valid: that a conjugation preserved in the Hitt. middle voice $-b a,-t a,-a$, which was not originally of the middle voice, created: a) the 
above-mentioned Hittite middle voice and, with certain variants, the middle voice of the rest of IE; b) the IE perfect, which was not originally a middle voice either, and which was not known to Anatolian, but which is of a later origin than the separation of this branch of IE. The perfect and middle voice arise from different oppositions of one and the same formation, not one from the other or vice-versa.

I should point out that the ideas I have just referred to on the secondary origin of the IE perfect, fit into a general conception: that which holds that the older type of IE possessed a system of monothematic verbs, preserved in Hittite, and that the more recent type possessed a secondary polythematic verb, pertaining to the rest of IE and heir to a later evolutionary phase.

Naturally, there is a series of details which are debatable and which should be studied in the light of new bibliography. But in general, one may say that several researchers have over the past few years independently arrived at approximately similar results to one another and to my own, which facilitate a new discussion of the problem. This discussion is necessary for there are still many problematical points and many differences of opinion. One might say that today the two theses which will be the starting-point of this paper are constantly gaining ground:

a) Anatolian (known chiefly through Hittite) is the heir to an older stage of IE, that which I have elsewhere termed IE II and which among other things is characterized by the fact that each verb has only one stem and that it had not yet developed stems such as those of the aorist, the perfect, the subjunctive and the optative. Nowadays, scholars such as Kerns-Schwarz (1972), W. Meid (1975, 1979), W. P. Lehmann (1974), W. Cowgill $(1975,1979)$, O. Carruba (1976), F. Neu (1976), W. R. Schmalstieg (1977), W. P. Schmid (1979), B. Rosenkranz (1979), subscribe to this thesis of the archaic structure of Hittite. One should note that this does not always strictly mean Sturtevant's Indo-Hittite hypothesis, based on the Stammbaumtheorie: sometimes (as in our case, for example) it is simply acknowledged that Anatolian did not participate in the more recent isoglosses of the rest of IE, as in the development of polythematic inflexion in the verb. This does not mean that it did not in turn have its own innovations.

b) The middle voice and the perfect are derived from a common Proto-Indoeuropean ancestor; the perfect arose in Post-Anatolian IE, with polythematic inflexion (the one I term IE III). This idea, which I already developed in my book of 1963, is now supported, with certain differences in the details, by J. Puhvel (1970), W. Meid (1971, 1979), W. 
Cowgill (1975, 1979), lately Kuryłowicz (1979), who had formerly put forward different solutions.

There is less agreement on what exactly was the form from which both perfect and middle voice were derived. Based on certain precedents by Neu (1969), W. Meid put forward a theory in 1971 which he re-asserted in 1979: the original, older form would be a «middle-perfect" or "Proto-Indoeuropean middle» with stative meaning, an injunctive more or less preserved in the preterite-presents of Germanic. From this point, the IE perfect would have been created and also the Hittite $-b i$ inflexion: it is accepted that the older form is preserved in Hittite in $-b a$, although the details are not clear, for there are doubtless innovations in it, too. Meid did not really work out the details, as he himself has acknowledged.

Neither are they sufficiently specified in Cowgill's latest paper (1979), who, despite the fact that he supports the Indo-Hittite hypothesis, believes that Anatolian lost the Indoeuropean aspect secondarily (for the opposite point of view, see my paper 1980 bis). There is, however, a coincidence with the former doctrine in that Cowgill attributes a stative meaning to his "nominal verbs" (thus he names the verbs in - ba, -ta, $-a$, following a line of thought which goes back to Kuryłowicz). He attributes this meaning to reduplication - I believe erroneously so. The following processes would have occurred secondarily in Anatolian: a) derivation from these verbs of an inflexion in $-h i,-t i,-i ; b)$ adscription of these -ha verbs to the imperfect (1st. sing. Luw. -ba, Hitt. -bun) of the verbs in -hi, according to Cowgill, with an imperfective value.

The contributions of these and other authors are important in that they acknowledge the existence of an older IE form with stative meaning which would be the basis for both the middle voice and the perfect (and the first, in turn, for the -hi conjugations); I wish to stress that the details are still lacking. On the other hand, there is today bibliography on an older IE «stative», which presents certain differences with regard to the $-b a,-t a,-a$ inflexion. I am not referring now to the long-known doctrine of the existence of statives, above all with a long vowel, in IE languages such as Germanic, Baltic, Slavonic and Latin (general orientation in Adrados 1963: 289 ff., 302 ff., 354, 458, 823 ff.), and also in Hittite (Watkins 1971), however much these statives form a highly useful parallel to those now in question. I refer rather to a series of papers which at times are not related to the problem of the antiquity of the perfect but which point to remains of an older stative different to the middle voice, within the Hittite -ha inflexion and in other comparable ones in other IE languages. Thus, Cardona in 1961 studied the middle

XLIX, $1.0^{\circ}-3$ 
voice endings of 0 . I. -é, -iré, to which he attributed this value, and which he assumed came from the perfect. N. Oettinger (1976) attributed only a third person stative to the oldest form of IE, which in sing. would take *-e (cf. Hitt. $-a(r i))$, ${ }^{*}-r e$; the middle voice and the perfect would be different, the $3 \mathrm{rd}$. sing. of the former would take *-to. These ideas are not far removed from those of H. Rix (1977: $135 \mathrm{ff}$.). In the third person he distinguishes between middle voice endings (with $-t$-) and stative endings (without $t-t$ : $3 \mathrm{rd}$. sing. $-a-t$ in 0 . I. dasayat, $-e$ in 0 . I. sáye, $-a$ - in Hitt. ištuari; 3rd. pl. -ra-n, -re in O. I., also $-r$, -ar in Umbrian and Celtic); in the second person -tha (in Hitt. -ta, O. I. tanuthās, Toch. parksatai, 0 . Ir. cluinte) would be opposed as a stative to *-so of the middle voice.

I am not going to discuss the details of these papers here, which differ from the former ones in that they do not deduce a middle voice and a perfect from the stative, but put them all together in the oldest type of IE as parallel categories. It is nevertheless clear that these studies arose from the same current of ideas which reacted against the hasty identification of middle voice and perfect and perceived in the stative a kind of common-ground for both categories.

This is really a promising step forward which should be combined with what is the most decisive contribution, in this case the work of Puhvel and Cowgill above all: that is, that there are too many differences between the middle voice (Anatolian and Post-Anatolian) on the one hand and the Indoeuropean perfect on the other, to assert any direct derivation of one from another or vice-versa. The - $a$ vocalism of the Indoeuropean perfect and its radical nature in only a few cases is found once more in the Hittite - $b i$ inflexion; the lengthened vocalism does not appear in this latter; as far as the middle voice is concerned, the - $b a$ inflexion has the same vowel degree as the active; there is nothing in Indoeuropean comparable to the -hi/-ha opposition; the systematic grammaticalization of reduplication is lacking in Anatolian and is obviously recent (cf. van Brock 1964); the meaning «state derived from a past action is missing; on the other hand, there is not always identity between the Hittite middle voice and the middle voice of the rest of Indoeuropean; we have already mentioned the differences in the desinential system. To sum up, there are too many differences simply to think that the perfect goes back to an earlier date to the separation of Anatolian from the rest of Indoeuropean.

This is clear, although the details of the earlier formation belonging to both branches, the source of the middle voice and the perfect, are not quite so simple. It is also clear that the attempts of Eichner (1975) and 
Risch (1975) to project the Indoeuropean perfect to a pre-Anatolian era have not met with approval. According to them, this perfect would have been turned in Hittite into a preterite, no more nor less than in Latin, etc.: into the -ba preterite (Hitt. -bun, which is considered contaminated by $-u n$ ) of the $-b i$ verbs. Certainly Eichner admits that some radical perfects were kept in Hittite as - bi verbs and that there was an extension which added $-b i$ to various derived stems. There are numerous reasons not to accept this argument; I restrict my references to the criticisms of W. Cowgill (1979: 26 ff.) and J. Kuryłowicz (1979: 144).

\section{Certain criticisms and problems}

Once the subject has been thus embarked upon, it is obvious that sound support exists which establishes a relationship between the Hittite $-b i$ and $-b a$ verbs, on the one hand and, on the other, the middle voice and the perfects of Post-Anatolian Indoeuropean, or IE III. It is no less obvious that there are still obscure points in this research, even once one acknowledges that an older Indoeuropean form with a characteristic ${ }^{*}-H$, a form which we shall provisionally classify as stative, on the one hand produced a middle voice with differences in Anatolian and Post-Anatolian, which may be interpreted in several ways, and on the other a Post-Anatolian perfect.

Before going into the subject in depth and expounding our own opinions, we are now going to tackle the problem from another angle. It seems that there is today sufficient consensus to examine the problem in the light of the tenets of the theory which postulates that each verb was inflected on only one stem at an older stage of Indoeuropean; and that in another even older phase not even endings existed, these being a secondary, although very old, creation, at the beginning of inflexional Indoeuropean or IE II.

If this theory is postulated as a starting-point (it is really the result of many studies and of the coincidence of many researchers' ideas), then the problem is to explain how and from which elements first the endings, then the oppositions of stems, were created. This is a problem which has intrigued researchers for a long time: I add to the list of studies given at the beginning of this paper, several books and papers which I have published since 1962 (Adrados 1961, 1963, 1965, 1968, 1970, 1971, 1975, 1979, 1980, 1980 bis). Doubtless one should also add contributions by other scholars. But I intend to pose the problem in the same terms as in two as yet unpublished papers of mine (forthcoming 1, 2), 
in which, with regard to other endings and stems, I put forward solutions which must be judged as applicable or otherwise to the forms we shall now study.

To exemplify with the $-s$, my suggestion is that, as against a form $R$ (a pure root), another form $R$-s was grammaticalized from an early date onwards in two types of oppositions. On the one hand, $-s$ was turned into an ending (first in 2 nd. 3rd. sing., and then reduced to the 2 nd.); on the other, it was turned into the marker of a deverbative verb, parallel to the basic radical verb without $-s$ and likewise with its own primary and secondary endings (if the meaning was the same or not, and in this case, which and from what date, is another question). The existence of these pairs of basic verb/deverbative verb is generally acknowledged today for the oldest type of inflexional Indoeuropean (cf. e. g. Watkins 1971, Lehmann 1974, Rosenkranz 1979).

However, at a second stage, either in IE III or Post-Anatolian, another different opposition was deduced from that of basic verb/deverbative verb, which in spite of all did not cause this latter one to disappear. This consists of the creation on the one hand of a preterite; on the other, and in different oppositions, of a subjunctive. Both are independent of each other; the subordination of the subjunctive to the indicative stems is a later phenomenon. Both the preterite and subjunctive take secondary endings. They are distinguished by a series of factors: the context, the use of different suffixes in one and the same verb when there is a danger of ambiguity, the avoiding of this by means of lengthenings or differences in the root vocalism, etc.

This is a model which is repeated in the creation of other deverbatives and later of other preterites and subjunctives with different stems. That invariably means the creation of a polythematic inflexion; at times, and at an earlier date, the creation of endings. The same formal elements create all these new functions and categories in different oppositions. Of course, before they were created, these formal elements had not that meaning: the meaning is precisely a product of the creation of categories and functions. For this reason, if in Anatolian formal elements coinciding with the aorist and the subjunctive are to be found, this does not mean that the aorist or subjunctive was lost, but that Anatolian inherited elements which were used at a later stage to create those new stems.

In view of this situation, and with regard to the elements now under study, that is elements ending in ${ }_{-}-H$, there arise a series of questions concerning their grammaticalization. Did they produce (and, should the answer be affirmative, when and how) endings, deverbatives, stems op- 
posed to the present? May one place within the general framework of Indoeuropean evolution what we know of the Hittite -hi and -ba forms, the Indoeuropean middle voice, the Indoeuropean perfect? Could the foregoing ideas help enlighten us on their history?

In order to attempt a reply to these questions we should first examine the history of the problem from a fresh point of view.

We have seen that the parallelism established from 1932 onwards, was between the Indoeuropean perfect in $*_{-} a, *_{-}$tha, ${ }^{*}-e$ and the Hittite middle voice in $-h a,-t a,-a$; besides these endings, they possessed in common a 3rd. pl. in $-r$. There arises a drawback, however: together with Hittite middle voice inflexion in -ha there not only exists an active voice in - $m i$, which was no surprise to scholars of Indoeuropean, but also another active voice in -hi, which did cause surprise. The temptation to consider this latter inflexion as secondary automatically arose, and thus the strange and almost universally accepted theory was formulated that the middle voice in -ha was converted into an active in - $b i$ by analogy to the active voice in -mi: *-hai >-bi, etc. This odd theory not only has phonetic implausibility against it and the unfeasibility of a passage from middle to active voice, but also many other contradictory factors of which we shall speak below. As far as we know, however, nobody has contradicted this theory, except for my book of 1963, a recent article by Jasanoff ( 1979 - phonetically and morphologically implausible, to my mind: $-h i$ would come from ${ }^{*}-H_{2} e$ and $-h a$ from ${ }^{*}-H_{2} \mathrm{O}$ ) and others by Beekes (1979) and González Fernández (1980) which we shall discuss.

On the other hand, the -hi verbs are, with regard to the - $m i$ ones, in a lexically conditioned distribution: with a few exceptions of verbs conjugated in either way, some roots are conjugated on the $-h i$ inflexion and others on the - $m i$ one in an unpredictable manner. In Rosenkranz's sampling (1969) of 3.000 Hittite verbs, he finds 2.453 in $-m i(73,7 \%)$ and 877 in $-h i(26,3 \%)$. At least in certain instances, the $-h i$ verbs have a stative value and a radical $a$ vocalism, which is interpreted as coming from ${ }^{*} o$. It is from these verbs that the perfect was deduced (or rather from their provious basis, supposedly before adding $-i$ to the tha so as to give the result $-b i$ ); in spite of all, they are still in a privileged position when the oldest stage of Indoeuropean is researched. For the -ba verbs, save a series of deponents, appear as the middle voice of active verbs in - $m i$ or $-h i$ and besides, do not present a vocalism or a stative meaning by which they could be assimilated to the perfect.

Thus the paradox has been reached that the starting-point for research (the - $h a$ inflexion) has, so to speak, been relegated to second place. From a partially preserved older Indoeuropean form somewhat 
modified in Hittite, on the one hand the middle voice and on the other the perfect, would have arisen. But it should be well understood that the older middle voice is still thought to be the basis of the Hittite - $b i$ inflexion (and of the perfect). For no other interpretation of the origin of $-b i$ has been found, nor, - $b a$ being a middle voice (opposed to - $h i$ ), has any possibility been found of denying that it might date from the Indoeuropean era.

On the other hand, the - $b a$ inflexion (and its parallel the perfect in *-a) was not easy to fit into the traditional tables of Indoeuropean -mi, $-s i,-t i$ inflexion. Hence the theory that it arose from the 3rd. sing. $-a$, that is from the thematic vowel ${ }_{-} e / o$ of an adjective or a noun, according to Kuryłowicz (1964: 62, etc.), Watkins (1969, p. $105 \mathrm{ff}$.) and Cowgill (1979: p. $33 \mathrm{ff}$.). This theory has produced a series of new interpretations: that the - $b a$ of lst. sing. (and eventually the -ta of $2 \mathrm{nd}$.) is an agglutination of pronominal origin; that the $-a\left(\mathrm{IE}{ }^{*}-O\right)$ of $3 \mathrm{rd}$. sing. is a thematic vowel and gave rise to no less than the whole of thematic inflexion; that this thematic inflexion was originally middle voice (for the Hittite $-b a$ inflexion is middle voice) and that it later became active, etc. A whole school of thought (Kuryłowicz, Watkins, Mme. Bader, Jasanoff) follows this line of research, which I shall criticize below. Cf. for the moment, Puhvel's criticism (1970) of the theory of the nominal origin of these forms, which he rightly terms pure undemonstrated assumption.

The fact is that Hittite sprang the surprise of a verbal inflexion in $-b i$ in lexical distribution with that in $-m i$, and of a verbal inflexion in - $b a$ either in lexical distribution (deponents) or opposed to those in - $m i$ or in $-b i$, or (with slight alterations) forming the preterite of the $-b i$ inflexion. It differs from the Indoeuropean perfect in $-a$, among other things mentioned, in that this is a case of one stem being opposed to another to indicate a different aspect, whilst $-b a$ is sometimes opposed to other endings to indicate voice and at other times is not opposed to other endings; it is a lexical fact, the same as - hi.

All this gives a remarkably obscure view of the problem of the origin of the perfect as one stem opposed to another (in the same way as the aorist and the subjunctive), as likewise of the origin of the personal and voice endings. It requires a new approach which would take advantage of the results obtained so far (the middle and the perfect as secondary results of a previous form) and which would perfect them within a new perspective of Indoeuropean evolution. 


\section{The origin of Hittite endings}

I believe that a new approach is needed to certain questions which are too quickly taken for granted. I believe that new light will be shed on the problem to hand if we can demonstrate that:

a) -ha and other endings are not originally of the middle voice.

b) $-b i$ and other endings are not derived from $-b a$, neither are they originally middle voice.

c) The basis of $-b a$ and $-b i$ is an ${ }_{-}-H$ stem with $\emptyset$ ending which was later lengthened. The ${ }^{*}-H$ was originally radical; then $-b$ - spread either as a characteristic of a deverbative stem or, with certain modifications, as a desinential marker.

A - ba verb is middle voice as against the same with a - $b i$ ending, although often no difference in meaning is found and other verbs (very many) take only - $h i$ or (as in the case of the deponents) only -ba, without one being able to attribute an active or middle meaning to

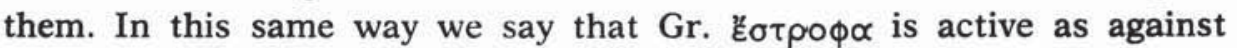

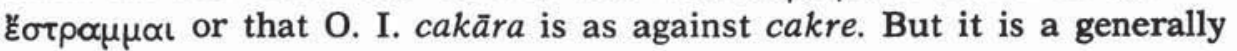
accepted doctrine that the middle perfect of Greek and Indian is secondary, being created from a middle present: it has polarized an older voiceless form in the active voice meaning, in the same way as Lat. uidi ( $<{ }^{*}$ uoidai) became active as against uisus sum. The data of other languages confirm the archaic nature of the perfect as a voiceless form; there is either no opposition of active/middle voice or if there is it is of a recent nature.

In view of this situation, a re-examination of Hittite data is called for. One must study whether the older stage is that in which $-b a /-b i$ are opposed or whether it is that in which either -bi or -ba appear without opposition of voice and with a purely lexical distribution (and the same goes for $-m i$ ). All the evidence leads one to believe that opposition is secondary. Not only because it is in general terms the most recent case and because even when a verb takes both - $b i$ and - ba often no semantic difference is found, but also because it is easy to imagine that $-b a$ and $-h i$ were secondarily opposed to create a «voice» opposition (one should bear in mind the parallel phenomenon of Greek and Indian perfects), whilst it is on the contrary not easy to imagine that an older opposition of voice became nearly always degraded to give an extremely important number of activa tantum and media tantum. It should be added that also outside Hittite activa and media tantum exist, frequently the same verbs: this is something which goes back to a remote date. 
The middle voice value of $-b a$ is of purely oppositional origin. It is certainly an old opposition, for in other languages, as is known, there exists a middle voice ${ }_{-}^{*} a i,{ }_{-}^{*}(m) a i$ (as against $-m i$ and thematic active voice) and also middle voice endings *-sai, *-tai and *-so, *-to more or less directly comparable to the $-b a,-t a,-a$ inflexion. But there are extremely clear traces left of the whole of this inflexion which was originally indifferent of voice. In Anatolian itself, apart from the media tantum with -ba, we have, as is well-known, the fact that -ba is in Luwian a 1st. sing. pret. active (in Hittite, there is -bun, which is usually explained by contamination with -un). However, this same form $-b a$ is found (with diverse secondary lengthenings) in 1st. sing. pret. midd. That is, that in the -hi/-ha verbs the form - ba was both present and preterite (it was atemporal), both active and middle voice (it lacked voice except when it was opposed in the present to $-h i$ ).

The same may be said of other endings of the -hi conjugation. In 2nd. 3rd. sing. the endings $-t a,-a$ function as middle voice against $-t i,-i$, as likewise in the -mi conjugation the ending -ta of $2 \mathrm{nd}$. 3rd. sing. functions as a middle voice against active $-s i$, -ti. Once more, however, in these two persons in the preterite, we find in the active voice of both conjugations both $-s^{s},-t$ and $-t a,-s t a$. The preterite preserves the non-distinction of voice better, although within Hittite there is secondary differentiation at times.

There is nothing strange about all this, given that both $-b i,-t i,-i$ and $-h a,-t a,-a$ are no more than the same series $-h,-t,-\emptyset$ followed in the one case by the lengthening $-i$, and in the other by the lengthening ${ }^{*}-0 .-i$ is characteristic of the present and the indicative, but not only in the active voice: if - $h i$ was polarized as an active voice this was through opposition to -ha, no more nor less than *uoidai (uidi) was polarized in Latin as an active form against uisus sum and to the contrary of how in 0 . I. *-ai (in cakre) was polarized as a middle voice against *-a (cakära). As for ${ }^{*}-o$, this was not originally characteristic of the middle or active voice either. We have just seen this with regard to *-to, "-sto, which figure in the active inflexion of the Hittite preterite, as also in forms of other languages without any voice meaning (thus, in O. Slav. $-s t \breve{u}, \mathrm{Gr}$. $\phi \alpha \dot{\tau}$, , which is indistinguishable from $\tilde{\varepsilon} \phi \eta$, etc.). This is not all, however; this doctrine should be applied in general terms.

I consider that $-b a,-t a,-a$ and likewise $-b i,-t i,-i$, which I have just explained as lengthenings of $-b,-t,-\varnothing$ are really lengthenings of $*_{-} H$ (generally $-\mathrm{H}_{2}$ ), if we go back to a more remote date. Kuryłowicz a long time ago perceived that in the $t$ (not palatalized before $-i$ ) of Hittite there was really an underlying ${ }^{*}-t H_{2}$ (cf. Gr. $-\theta \propto$ ), which was explainable 
by means of a metathesis of ${ }^{*}-H_{2} t$. To my mind, the starting-point of these endings is in roots and stems in a laryngeal: dabbi, tarnabbi precisely represent this starting-point, here the ${ }^{\star} H\left(H_{3}\right.$ in the first case, $-H_{2}$ in the latter) is etymological, which explains its presence in both 1st. and 2 nd. sing. It also implies that in 3rd. sing. there had been an ${ }^{*}-H$, which was lost. Neither the gemination of the ${ }^{*} H$ in 1st. sing., nor its loss in 2nd. 3rd. sing. (for there must originally have been one here, too, if it was radical) should seem strange. I have elsewhere given sufficient documentation of this type of phenomena in Hittite, where the laryngeals were being dropped and preservation, gemination and loss all occurred (cf. Adrados 1961: 65 ff., 1963: $100 \mathrm{ff} ., 1970$ ). What Hittite did was to take advantage of this state of vacillation in order to characterize the different persons grammatically: the 1st. sing. with the geminate, the 2nd. 3rd. with the loss of the phoneme. But there is a phonetic trace of it in the 2nd. (the non-palatalization of $-t i$ ) and in the 3rd. (geminations such as that in sakki, cf. on them Bernabé (1973) and Watkins (1975)).

Now, from the moment of reaching an opposition ${ }^{*}-\mathrm{Hi},{ }^{*}-\mathrm{tHi}<{ }^{*}-\mathrm{Hti}$, ${ }^{*}-\mathrm{Hi} /{ }^{*}-\mathrm{Ho},{ }^{*}$-to $<{ }^{*}-\mathrm{Hto},{ }^{*}-\mathrm{Ho}$, which later evolved as we know, there arose in Anatolian a series - $h a,-t a,-a$ which doubtless corresponds in the rest of Indoeuropean to ${ }^{*} a$, *-tha (because the timbre of $\mathrm{H}_{2}$ predominated, being the most frequent laryngeal), ${ }_{-} o$, although $*_{-} e$ was generally preferred (not in the thematic inflexion of Baltic). The ${ }^{*}-o$ or ${ }^{*}-e$ kept their timbre for the laryngeal was lost at an early stage. But in the 1st. and 2nd. persons, one must assume the older existence of this same vowel, the so-called thematic one; therefore, the thesis of the pronominal agglutination is useless. However, there is no reason to suppose that this vowel ${ }^{*} e / o$ of the $3 \mathrm{rd}$. sing. had an old middle voice meaning. Neither is there one for the same ${ }^{*}-o$ when it was added to $-H$ or $-t$ : we have already seen this.

Really, in the same way as we find traces of *-Ho and *-to in active and middle voice and as we have deduced that the voiceless use was the original one, the others being secondary as a result of polarizations, this also occurs with mere ${ }^{*_{-} o}$ ( or ${ }^{*_{-}} e$ ). There is middle voice ${ }^{*_{-} o}$ in thematic forms such as 0 . I. 1st. 3rd. sing. duhé, 3rd. sing. sec. áduha (cf. Ambrosini 1965, among other bibliography). But forms such as Gr. $\phi \varepsilon \rho \omega$, $-\varepsilon เ \varsigma,-\varepsilon t$ and other corresponding ones are active thematic, as well as the Baltic one with vocalism ${ }^{*}-o$ (cf. Watkins 1975). It is today acknowledged by practically all that in $-\varepsilon \mathrm{l},-\varepsilon \mid \varsigma,-i$ is a simple lengthening and $-s$ a hypercharacterization. That is: there is $*_{-} e / o$ in both active and middle voice, precisely ${ }^{*}-\mathrm{Ho}$, ${ }^{*}$-to, which are no more than the result of adding ${ }^{*}-O$ a root with or without lengthening. 
There is no reason whatsoever to consider that ${ }^{*}-e / o$ was at an earlier stage characteristic of the middle voice, and even less when today there is general agreement that at least the endings *-so, *-to are no more than lengthened $-s,-t$ : it is also agreed that $-s,-t$ originally had no tense or voice meaning. Cf. for example, Schmalstieg 1977. I cannot quite understand certain scholars' insistence on this point, above all that of Watkins and Mme. Bader (1972, 1974, 1975, 1976, among other papers). Although I do not personally believe in a nominal origin for the forms which created the perfect and the middle voice (the thesis of Kuryłowicz, Watkins, Cowgill), if things had happened in this way, this would be one more reason for refuting the middle voice meaning of *-e/o: the noun and the adjective have no voice and the passive meaning of certain participles is secondary. Moreover, if, without supporting this theory, the use of the thematic vowel in the noun and the verb is compared, it may be clearly observed that the variations of timbre and quantity were used in the noun to differentiate the cases: a parallel evolution may be postulated for the verb. If Lat. $d o$ comes from ${ }^{*} d e H_{3}$, there is here an ${ }^{*} \bar{o}$ of laryngeal origin (radical); it is not necessary, on the other hand, to introduce laryngeals in order to explain the $-\bar{o}$ of Gr. $\not \gamma \omega$, etc. It is a simple lengthening such as that which makes *urk $k^{*} o s$ -originally indifferent of number-into a plural *ur $k^{*} \bar{o} s$, *urk $k^{*} o s$ being polarized as a singular.

I shall nevertheless leave the problem of the thematic vowel itself and return to it later. I had stated that, to my mind, -ha is originally indifferent to voice, as likewise the other forms of its paradigm, being polarized later as against - $b i$ and other forms, also indifferent to voice in their beginnings. It is precisely important to stress that it is today an almost general opinion that in primitive Indoeuropean there were two series of verbs, some for action and others for states of being (or nominals, the definition varies): the first are those with endings corresponding to Hitt. $-m i$, $-\varsigma i,-t i$; the second, with those corresponding to $-b a$, $-t a,-a$. This is the opinion, for example, of Neu (1968), Watkins (1969), Mme. Bader (1974, 1976, 1978), Cowgill (1979). It should be noted that if this is so (and I believe that this is an incomplete description of the facts), it implies that these were two series of forms which were not polarized one against the other, for their distribution was lexical: either depending on the origin of the inflexion (nominal or verbal) or on the meaning, or else on both factors. These two series could therefore hardly give expression of a grammatical category such as voice, which implies the opposition of two forms of the same stem. If things are as 
we are told they are, it seems clear that the middle voice use of $-b a$ as against $-m i$ (and $-h i$ ) is secondary.

In fact, if Mme. Bader (1974: p. $11 \mathrm{ff}$.) states that in the oldest type of Indoeuropean a verb belonged either to the $-t$ inflexion or to the ${ }^{*}-e$ one (exemplified in the third persons), and that in the former case it was active and in the latter middle voice, this is hard to understand if one has a structural approach to language. If it were a case of two endings which were alternatively joined to the same roots and opposed, it could quite well be understood. But exactly the opposite is postulated: as we know, the distribution is lexical. However, without any explicit opposition, no grammatical category is possible. When $-t i$ and ${ }^{*_{-} e}$ were opposed, the middle voice did arise, but not before this. The proof is that the active and middle voice meanings do not occur in the activa tantum and media tantum verbs, but in those which present opposition of the two series of endings. $-t i$ (and the whole - $m i$ series) was neither active nor middle voice, *- $e$ (and the whole ${ }^{*}-H o$ series) was neither active nor middle voice. Neither were they tense markers (- $t i$ only came to be so through opposition to $-t$ ).

With this, we have still not entered into the study of the - $b i$ inflexion in depth, which to a certain extent is a problem because it is not found outside Hittite, and because on the other hand, it has certain traits in which it resembles the perfect. It is in Hittite a relatively frequent inflexion, approximately $25 \%$ of the verbs in Rosenkranz's sampling, whilst the $-b a$ forms are approximately $7 \%$. I have already said that the solution almost invariably adopted is that of deducing -bi from *-ha-i, which presents a series of implausibilities and which, on the other hand does not clear up the problem of the relationships between the various forms we are studying.

Really, the reasons are the following for explaining the $-b i,-t i,-i$ forms as derivates of merely adding an $-i$ to the laryngeal, as likewise the other series adds ${ }^{*}-o$ or ${ }^{*}-e$ :

1. *-bai, *-tai, *-ai > -bi, -ti, -i is not phonetically feasible.

2. - $h i$, etc. have their distribution on a fundamentally lexical basis and at times have their own semantic value and form. It is from here that one should start to explain these forms, rather than from a secondary opposition to $-b a$, etc. (which for the rest does not require an older *-bai, etc., either; besides, - $b a$ is sometimes opposed to -mi, not to $-b i$ ).

3. If $-m i,-s i,-t i$ are more recent than $-m,-s,-t$ and were created to oppose present to preterite (they are not derived from *-mai, *-sai, *-tai), 
it is equally logical that the same should happen with $-h i,-t i,-i$ from ${ }^{*}-H,{ }^{*}-H t,{ }^{*}-H$.

4. The reason that the pure form without $-i$ was not kept in the preterite of these verbs is because the evolution then being undergone by the laryngeals made persons difficult to distinguish. Therefore, forms with final ${ }^{*}-o$, indifferent to tense, were taken.

All this implies that at a certain moment the forms with ${ }^{*}-H$, either radical or belonging to the stem, could inflect with ${ }^{*}-H,{ }^{*}-H t,{ }^{*} H$ or with ${ }_{-}-\mathrm{Ho},{ }^{*}-\mathrm{Hto}{ }^{*}-\mathrm{Ho}$ : the distribution was lexical as there was no voice or tense meaning. They were, in fact, stems with $\emptyset$ endings in 1st. 3 rd., with $-t$ ending in 2nd.: they occurred at times in different roots, at others in the same one (and thence their grammaticalization as voice markers). In the beginning, the whole of this inflexion was allomorphic with the inflexion in $-m i,-s i,-t i$; the distribution was lexical and there was no semantic difference. However, this difference began to be created later in some cases.

Finally, I should like to point out that things are not much different if one follows Beekes' ideas (1974), adopted by González Fernández (1980), and according to which $-b i,-t i,-i$ are not a secondary derivate of $-b a,-t a,-a$, but an older form with $-i$. Based on the fact that the oldest type of Hittite spelling is 1st. sing. -he, but 3rd. sing. $-i$, and that phonetic evolution from forms with *ai seems impossible, Beekes concluded in fact that -he (and therefore $-h i$ ) must come from ${ }^{*}-\mathrm{H}_{2} e i$ or ${ }^{*} \mathrm{H}_{2} \mathrm{Oi}$ and $-i$ from * ${ }^{*} i$ or ${ }^{*}-i$ : these are the phonetic possibilities. González concludes (I believe rightly) that it is therefore logical to start from ${ }^{*}-\mathrm{H}_{2} \mathrm{O} i{ }^{*}{ }_{-}-\mathrm{H}_{2} \mathrm{Oi}$,

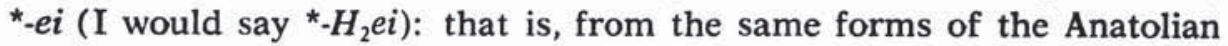
middle voice, except for the variant ${ }^{*_{-} e}$ in $3 \mathrm{rd}$. sing. (as in the Indoeuropean perfect), and with $-i$.

In fact, the same series of endings, on the strength of a thematic vowel and a $-t$ lengthening in 2 nd. sing., would have been specialized both for the present (with $-i$ ) and for the preterite (Luw. -ha); the middle voice would have preserved the form without $-i(-h a,-t a,-a)$. In fact, as we stated, what turns forms with a thematic vowel into middle voice forms is a secondary differentiation. If (as in Adrados 1963) I prefer the explanation of $-h i,-t i,-i$ as coming from ${ }^{*} \mathrm{H}_{2}$ followed by $-i$, it is on account of the parallel to $-m i,-s i,-t i$ and of the existence in Indoeuropean of forms with a pure stem and $\emptyset$ ending (see below). I insist, however, that the consequences come to much the same thing for the point under discussion here. 


\section{Origin of the perfect and middle voice forms}

We have come to a point in our research of the Hittite endings at which we are obliged to conclude that their temporal and voice differences are secondary; although, obviously, the differentiation of tense and voice is far earlier than Hittite because it is found with some or other formal details in Post-Anatolian. However many traces there are here and there of an older temporal and aspectual indifference in the forms, in general terms the differentiation dates from the beginning of IE II.

Another result of this research is that, together with the endings $-m i,-s i,-t i$ (in which the assignation of $-s$ to the 2 nd. sing. and $-t$ to the 3rd. sing. is secondary, cf. Adrados 1963: p. 638 ff., Schmalstieg 1977 bis), the $\emptyset$ ending is frequently used. What we attribute to Hittite with its original identity of 1st., 3rd. sing. pure stems which were later distributed by means of a phonetic device, is no different to what happens in the thematic verbs of other languages, in which the opposition 1st. ${ }^{*}-\bar{o} / 3 \mathrm{rd}$. $*^{*}-e$ ( or * $-o$ ) lies on the contrary in the system of alternations. However, at the beginning, the distribution of one or another type of endings was basically lexical, although there is no doubt that the same root could at times use one or the other of them: this may be deduced not only from the Hittite "mixed" inflexion, but also from the differences between the desinential systems of other languages, the existence of semithematic inflexion, etc.

We cannot go into the details of this here. It is however clear that the endings, the origin of which is either in lengthenings or in a radical element such as ${ }^{*}-H$ which soon spread far outside its verbs of origin, had no other function than that of marking persons, in as far as these latter were marked; or, when -ti/-t were opposed, tense. Even in the case of persons this left much to be desired: there could be either $-s$ or $-t$ in 2 nd. and 3rd. sing., and the endings were pure lexically conditioned allomorphs or in free distribution. They had nothing to do with voice, tense or mood, merely with person.

At this point, we take up once more the thread which we had dropped at the beginning of paragraph II: the study of how a lengthening -of radical origin in this case- which gave endings, namely $-H$, also became grammaticalized in several other ways.

As we have said, IE II grammaticalized certain lengthenings in two ways: as endings and as markers of deverbative verbs, with or without a meaning distinction with regard to a basic verb. Now, as far as our 
$-H$ is concerned, we should state that there was also this second grammaticalization. There were two phenomena as we have already pointed out:

a) Compared to the - $m i$ verbs, those in -bi appear in lexical distribution, but at times they have a stative value and a radical $*_{-o}$ vocalism.

b) Compared to $-m i$ and $-h i$ verbs, those in -ha are sometimes one lexical variant more, but at other times they are opposed as a middle voice against the active voice.

Although ${ }^{*} H$ was radical at a very early date, from the moment in which it spread beyond its roots or stems of origin and became a common element as against the two lengthenings $-i$ and ${ }^{*}-o$, it became a truly non-desinential element: that is, a sort of lengthening itself. Moreover, this lengthening, not only by itself but joined to ${ }^{*}-0$, was grammaticalized by opposition to $-m i$, $-b i$. Although we classify this grammaticalization as "voice», if one considers it carefully, it is really no different from other phenomena we classify as an opposition of basic verb / deverbative destined to mark a specific Aktionsart.

The concept of voice, in fact, arose before the discovery of Hittite. In a language such as Greek we distinguish voice from the other categories because it is multiplied by all of them: there is active and middle of the present, future, aorist and perfect in their different tense, mood and noun forms. On the other hand, the other categories are marked by means of diverse suffixes or characteristics; from the point of view of Greek (and of the other Indoeuropean languages as from a given moment onwards) voice is marked only by the endings.

But we shall now turn our attention to Hittite and the linguistic model it represents for us: IE II. From this point of view, the middle voice is no different to any other Aktionsart marked by a second stem opposed to the basic verb. As there are suffixed verbs opposed to a radical verb and as both mark different Aktionsarten, in opposition to many verbs there is likewise another one which marks the middle voice meaning (intransitive, stative, reflexive, passive...). The bases of future evolution are securely established in this way. The laryngeal "suffix» is no longer to be seen in Hittite, only a - bh- is left as 1st. sing. marker; the endings are different to those of the active; the middle voice may refer to both basic verbs and deverbatives. One step further and the middle voice became a form distinguished only by endings and derived from all the new stems which were being created. That is, that the first signs of the future middle voice at the beginning of IE II, before the creation of the Hittite we know, represent in fact something which 
was characteristic of this type of Indoeuropean: the coupling of stems, of which the second gives a semantic difference with respect to the first. It should be well understood that this was not a systematic coupling and only occurred in some verbs. In others it did not occur: there are independent $-b i$ and $-h a$ verbs, as there are also ones with $-s k$ and the nasal suffixes.

This deverbative, the older middle voice, was, apart from the reasons given above, distinct from others on account of its formal vacillation $\left({ }^{*}-H /{ }^{*}-H o\right.$, later $\left.-h i /-b a\right)$ and because in its oldest stage it did not oppose two tenses but was a sort of injunctive; there are important traces of this left in Hittite, as we saw, as also outside it in as far as the perfect only at times and secondarily, was reduced to the present by means of opposition to a new preterite (thus the past perfect of IndoGreek.).

The above-mentioned deverbative, which is placed both in the origin of the Hittite middle voice and, in the rest of Indoeuropean, in that of the perfect, is the stative to which we refered above when quoting papers by various authors. We spoke precisely of other statives in Hittite and outside it, which were included in the present stems. This, then, is a similar case.

But at this point we enter a new period of the history of Indoeuropean: IE III, characterized by the creation of various stems which were opposed to that of the present (aorists, subjunctives, etc.). We must now study how this occurred.

Moreover, we must study this not so much from the formal point of view, in relation to the details of the different types of perfect in the different languages, their chronology, etc., which will not be discussed here, but from general points of view. We must reconstruct the oldest nucleus of the stative, an old deverbative which prior to Hittite developed the forms we call middle voice and which, on the other hand, gave rise to the perfect at a later date.

Eichner's paper (1975), whose thesis of the conversion of the old perfect to the Hittite preterite I do not find acceptable, on the other hand supplies highly interesting material on the history of the Hittite $-b i$ conjugation. He rightly describes (Eichner 1975: p. $85 \mathrm{ff}$.) how the nucleus of the Hittite $-b i$ verbs is the present-perfects with stative meaning, radical and with *o vocalism, of the type of $a k-/ a k k$ - $\alpha$ to die», ispai- / ispiina- (with alternating vocalism), "to satisfy oneself», etc. He himself compares them with the present-preterites of Germanic of the type of Goth. wait «I know»: forms which Meid had previously compared with the Proto-Indoeuropean stative. 
It should be noted that verbs like these, alongside which others from other languages may be mentioned (Gr. ot $\delta \alpha, \mu \varepsilon \varepsilon_{\mu} \eta \mu \alpha \mathrm{L}$, Lat. ōdi, me. mini, etc.), also present at times other stems of the same root, but they are actually isolated and lack voice and tense relationships. They inherit the situation of the Hittite -hi preterite-presents, not that of all the - $-b i$ verbs which were widespread. Neither do they inherit the -hi endings, but those of the -ba verbs. Evidently, the perfects of IE III, apart the fact that concerning vocalism, reduplication, etc., offer certain innovations and do not exactly have their starting-point in the Anatolian known to us. This starting-point is in a previous linguistic phase in which - $b a$ verbs existed which were otherwise identical to the - $h i$ preterite-presents of Hittite. For this latter only sometimes offers -ha verbs as being radical and isolated; they are generally middle voice forms as against the active $-h i$ or $-m i$ forms and have no differences in vocalism compared to these latter.

However, this development of the -ha verbs is not exclusive to Hittite: it is the development which produced what we call the middle voice, a process of dislexicalization, of the opposition of a * $h a$ verb to another verb from the same root or stem, which, as we have stated, is typical of all Indoeuropean and not just of Hittite. This nevertheless occurs at times with important formal differences (of the types *-(m)ai, *-sai, *-tai, etc., outside Hittite). Together with this development the creation of the Indoeuropean perfect in stage III is another process of dislexicalization: the stem of the perfect is opposed to a present stem, also to that of the aorist. Contrary to this latter, this process took place without marking tense or voice at the beginning.

Another remark which should be made is the noteworthy fact that the Anatolian preterite of the -hi verbs had similar forms to those of the perfect and middle voice: 1st. sing. Luw. -ha, 2nd. 3rd. sing. -ta (among other forms), 3rd. pl. - $r$. It is not that we believe, as has been suggested (Eichner and Risch) that this is an old perfect turned into a preterite, nor even, as has also been suggested (González Fernández 1980), that this is the beginning of a means of marking the preterite which later culminated in the western languages such as Latin, when a new stem was introduced together with endings of this type. But this fact needs explaining. We believe, in fact, that it is an old atemporal use of the -ha inflexion, which was later polarized as a preterite as against the $-h i$ forms. It is a typically Anatolian phenomenon and is a good example of the older lack of tense and voice of these endings.

In fact we are going to summarize this doctrine, which marks the successive phases of evolution, in the following table: 
Indoeuropean I (pre-inflexional)

1. Radical, not grammatical, $-\boldsymbol{H}$.

Indoeuropean II (monothematic)

Process

2. Spreadıng of allomorphic *-H, *-Ho, with lexical distribution.

3. Wider spreading of ${ }^{*}-\mathrm{H} /{ }^{*}-\mathrm{Ho}$, with oppositive distribution (with the same root or stem).

$\checkmark$ 4. Diverse Anatolian evolutions.

\section{Function}

a) They contribute to marking endings.

b) They give statives.

*.Ho / *.H, - $m$ mark voice (but function a) subsists).

$$
\begin{aligned}
& -H \text { becomes hi which ab- } \\
& \text { sorbs the stative meaning } \\
& \text { (but tha marks this in the } \\
& \text { preterite). }
\end{aligned}
$$

Indoeuropean III (polythematic)

5. Generalization (not total) of *-Ho in oppositive distribution (that is, being opposed to another form of the same root or stem).

6. Diverse formal innovations.
Creation of the perfect, with various formal markers.

The voice system is completed and extended to the various stems.

We would add that the perfect of IE III did not always eliminate the old ${ }^{*}-H$ form. A Gr. form $\pi \dot{\varepsilon} \phi \eta$ is a very clear case of the non-diffusion of $\star_{-} \mathrm{H}_{2} \mathrm{O}>-a$ and there are several others. However, they can only be suitably explained by applying the theory of the laryngeals with velar appendix, which I have not taken into account here in order to make my exposition easier to follow. I refer to perfects such as $\mathbf{O}$. I. jajñáu, dadáu, Gr. ${ }^{*} \beta \varepsilon \beta \lambda \eta \nu,{ }^{*} \tau \varepsilon \theta v \bar{\alpha} u$ (deduced from the participle), Lat. plēui, sẽui, etc. Cf. Adrados 1975: $699 \mathrm{ff}$.

I should also mention the fact that the old stative not only subsisted in Anatolian together with the new middle voice form, but also in IE III. I have already passed a few remarks on this, but I should like to add certain details. Not only the preterite-presents and the so-called

XLIX, $10^{\circ}-4$ 
statives of Baltic, Germanic, etc. (with ${ }^{*}-\bar{e}$ and other markers) fall into this category, being inflected according to the regular conjugation. Originally, some or all of the so-called proterodynamic presents, with radical stress and full or long vocalism, probably fall into the same category. J. Narten (1968) has studied these and Beekes (1973) has tried to explain them as coming from the perfect. This idea of making any anomalous vocalism of the athematic presents come from the perfect is a widespread notion, cf. also, for example, Kuryłowicz (1975) on the *-eie/o iteratives of Slavonic and Baltic. One should rather consider that certain stems specialized as statives, which are in turn the origin of the middle voice and the perfect, had as formative element vocalisms $\left({ }^{*}-0\right.$ and lengthened degree) which were found in some presents at a monothematic stage (Cf. Adrados 1963: $670 \mathrm{ff}$.). This is the same thing as happened with the lengthenings with $-h$ and reduplications.

Thus, in fact, we have seen that the evolutionary process of Indoeuropean *-H stems is not much different from that of those other stems which, apart from endings, produced deverbatives, and later, in IE III, stems coupled to others. There are withal certain differences. The statives on the one hand produced a middle voice comparable to other deverbatives, but which had special characteristics for it could be multiplied by the different stems which arose in the process. This occurred while still in the stage of IE II. In IE III, the same stative created the perfect when opposed to verbs of the same root. Its function was not to mark tense, the original function of the preterite which was later combined with an aspectual one, the aorist; it was purely aspectual. The perfect did not mark tense and, for a long time, on the contrary to the aorist, it was left outside the category of voice. It did however mark not only a stative aspect but, more precisely the state of the subject as a result of a past action. As such, the perfect was opposed to the ensemble of present and aorist: the oldest aspectual opposition is that of stative / non-stative. The aspectual opposition present / aorist, which I have already discussed, is more recent and is most probably restricted to Indo-Greek alone. It was born of the existence of two past tenses, the preterite (aorist) and the imperfect, when the moods were subordinated to the indicative stems; and likewise of the opposition which was created between the moods (and nominal forms) of present and aorist.

The subordination of the moods to the perfect must have taken place in the same way as their subordination to the present and aorist and likewise the subordination of the nominal forms. The participles, in particular, are very old adjectival forms which were secondarily adapted to the perfect in a limited dialectal area. But we cannot go into the 
details of these phenomena here, neither into those of the creation of the preterite of the perfect (the past perfect) and its middle voice.

As regards the middle voice in general, one should add to the foregoing the details of the evolution of its desinential system, both in Hittite and in the rest of Indoeuropean. Although certain differences exist between some languages and others, Hittite shows that the basic lines of evolution, with regard to form and semantics, were marked from IE II. For example, the presence of *-to- in 3rd. sing. instead of the simple thematic vowel, preserved in remains, is characteristic of the middle voice, cf. e. g. Ambrosini (1962), Meid (1975: $216 \mathrm{ff}$ ), Rix (1977: p. $135 \mathrm{ff}$.): now, in the Hittite middle voice we already find -ta (and -tar, -tari) together with $-a$. I believe, however, that the active/middle voice opposition is not a universal isogloss in Indoeuropean (see below). But wherever it appears, its meaning is the same; to the well-known data of Greek, Latin and Old Indian, those of Hittite (Neu 1968: p. $54 \mathrm{ff}$.) and Tocharian (K. T. Schmidt 1975) may be added.

We may sum up our conclusions in the sense that a study of the origin of endings and stems would not be fruitful if it were based merely upon forms without taking the oppositions into account. Only when a lexical distribution is made into an oppositive one (two endings or two stems opposed to each other as enlargements of the same root) are categories created and formerly non-existent meanings of the forms used defined. Or, if they were pre-existent at some time, this was with a purely semantic and still not grammatical value. Neglect of this principle has led to too many aprioristic definitions of the original meaning, for example, of the thematic vowel (supposedly a middle voice meaning whilst the category of the middle voice is secondary), of the perfect, of the $-b i$ inflexion.

All this should be completed with a study of the perfects (and preterites) in $-\mu,-\mu a(i)$, to which we shall devote a special forthcoming paper).

\section{More on the thematic vowel, the $\emptyset$ ending and the middle voice}

This paper would not be complete without my corroborating certain points of the foregoing with specific data and interpretations as far as the thematic vowel and the origins of the middle voice are concerned. I had to leave these on one side for the time being in order not to disrupt the main line of argument. 
I have already given the reasons for which I do not consider as acceptable the classification of the thematic vowel as originally a «middle voices element: a middle voice characteristic of the $3 \mathrm{rd}$. sing. of the perfect (and of the -ha inflexion) later extended to certain verbs, which then became a thematic vowel with a middle voice meaning that only at a later date obtained active inflexion. Any thematic verb would be recent, any active inflexion of a thematic verb would be even more recent: even a thematic 1st. sing. $-\bar{o}$ would come from a middle voice "suffix* * $-\mathrm{oHo}$ (others say from * $\mathrm{oH}$, an opinion which Watkins, quite wrongly, attributes precisely to me (1969: 109)).

This theory has given rise on the one hand to constructions which I would call aprioristic, such as for example, those of Mme. Bader with regard to the history of the inflexion of the verb "to be» (Bader 1976) or to the Hittite thematic presents (Bader 1975); on the other hand, it has caused exaggerated reactions which discover active thematic forms everywhere, thus Georgiev $(1975,1978)$. I do not doubt, however, that these scholars are right in the starting-points of some of their conclusions. For the rest, these and other articles by Mme. Bader make contributions of the greatest interest (e. g. on the opposition of stems, on adverbial lengthenings, on the nominal and verbal uses of the same lengthenings, etc.). But I believe that there is not sufficient ground, I repeat, to postulate for example that is "to be first had an athematic middle voice inflexion ${ }^{*} s \bar{o}$, ${ }^{*} s t h a,{ }^{*} s e$, then a thematic middle voice *sō, later active forms (secondary ones *som, *ess, *est, later primary ones *esmi, "essi, "esti). It would suffice to state that *sō is only witnessed in Tocharian B ne-sau, an analogical form to the general au in Tocharian B.

I believe, however, that I have no need to criticize these theories in detail, for I consider it useless after having demonstrated that $-e / o$ is not originally a middle voice form.

On the other hand, I do not doubt that they are to a certain extent justified: the spreading of the thematic vowel is secondary and its morphological usage relatively recent. We often find semithematic inflexions in the verb which there is no reason to interpret invariably as secondary ones, products of the degradation of the thematic vowel: on the contrary, they are an archaism which connects Hittite with western languages and the elimination of which is one of the innovations of the Indo-Greek dialect (cf. Adrados 1963: 605 and many other places). They come from the epoch in which the thematic vowel spread.

I believe, in effect, that one should reconsider the whole question of the thematic vowel, its original indifferent meaning and its diverse 
successive grammaticalizations: only in this way would it be possible to lay the ghost of its supposed «middle voice» origin once and for all. In my books of 1963 and 1975, I contributed many points which had not been studied in later bibliography. Obviously one can go even further. On the other hand, it is not my intention to repeat these points here, neither to insist on the hypothesis expounded there on the origins of the thematic vowel: this latter would be an element taken from the full degrees of several lengthenings or suffixes $(-e / o s,-e / o i$, etc.). But if it is a sound principle to consider the verb and the noun simultaneously in the research of the evolution of Indoeuropean (cf. Meid 1979: 212), I believe that to draw attention to the parallel between the nominal and verbal use of the thematic vowel may be useful in dispelling the mirage of its supposed older middle voice meaning.

To begin with, the place of origin of any thematic vowel in the verb could not have been exclusively in an athematic $3 \mathrm{rd}$. sing. in ${ }^{*}-e$ or ${ }^{*}-o$, which was then interpreted as thematic. If it is true that this form comes from a noun or adjective in ${ }^{*} e / o$, then it comes from a thematic form and a cycle arises of thematic form-athematic one-thematic form once more, which is implausible. Besides, as we have already stated, this nominal form was not of the middle voice, neither is the perfect or -ba inflexion so except by a partial and secondary opposition. Whether this theory be correct or not (I personally believe that nothing can justify

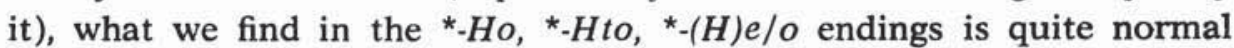
both within the verb system and in that of the noun. If one had to dispense with the hypothesis of ${ }^{*_{-}}(\mathrm{H}) e / O$ with loss of ${ }^{*} H$ and if the original form was merely $*_{-} e / o$, the same would apply.

Disregarding what might be the origin of the thematic vowel, it is clear that this was used formally in the same way in both verb and noun almost always and even in the first terms of compounds which at times reveal the older non-distinction of noun and verb. This is something which goes back in fact to pre-inflexional Indoeuropean (IE I), although it later underwent certain formal variations in the nominal and verbal fields. Of course, there were also serious variations in meaning for, with the exception of number, the categories and functions are different: the grammaticalizations of the thematic vowel are, therefore, different.

It think it would be useful to give a table of the different distributions of the thematic vowel $e / o$ in relation to the root $(R)$, to the $-i$ lengthenings of deictic origin and to the lengthenings of nominal-verbal roots $-s,-t$, $-m,-r$, and ${ }^{*}-H$. The main extant types are the following: 

a) $R / R-i$
b) $R / R-e / o$
c) $R / R-s\left(-t,-m,-r,{ }^{*}-H\right)$
d) $\mathrm{b}+\mathrm{c}$ lengthenings $(R-e / o s$ $\mathrm{b}+\mathrm{a} \quad \forall \quad(R-e / 0-i \ldots \ldots \ldots . . .$.

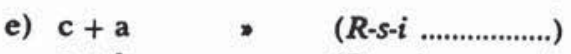 $\mathrm{c}+\mathrm{b} \quad$ $\quad(R-s-e / o \ldots \ldots . . . . .$. $\mathrm{c}+\mathrm{b}+\mathrm{a} \quad$. (R-s-a-i .............)
f) $\mathrm{b}+\mathrm{a}+\mathrm{c},(R-e / o-i-s \ldots \ldots . . .$.

One should note that the types from a) to d) are common to noun and verb, whilst those e) and f) basically appear in the verb which is more fully evolved. Type b) is in nominal forms such as Lat. domine and the instrumentals in ${ }^{*}-\bar{e},{ }^{*}-\bar{o}$, in verbal forms such as Gr. ör $\gamma \varepsilon$ (imperative), Baltic 1st. sing. ${ }^{*}-\bar{o}$, 3rd. ${ }^{*}-o$ (Watkins 1975). Type c) is in the noun that of many suffixes and endings, in the verb that of these same suffixes when they are added in the $\emptyset$ degree and that of endings such as $-m,-s,-t,-r$. Type d) is in the noun and the verb that of these same suffixes and endings when they are added in the full and lengthened degrees. If this occurs before an ending, we speak of thematic inflexion (sometimes semithematic), but this thematic vowel may be grammaticalized to express, for example, the subjunctive as against the indicative (a thesis I expounded in 1963 and is now quite widespread, cf. Kuryłowicz 1964: $137 \mathrm{ff} ., 1977$ : $90 \mathrm{ff}$., Meid 1979: $172 \mathrm{ff}$.) or the present as against the aorist (Gr. $\left.\delta \dot{\alpha} \alpha \mu_{\alpha} / \xi_{\varepsilon} \delta v\right)$ or on the contrary (Gr. $\left.\chi \varepsilon^{\varepsilon} \omega / \mathcal{E}_{\chi} \varepsilon \alpha\right)$. In the noun type d) is grammaticalized, opposed equally to type c) or athematic,

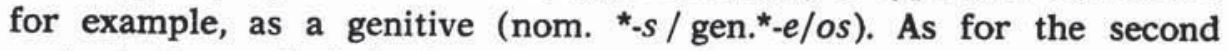
variant of type d), it is that of e. g. Gr. coyet whe carries»; from the IE point of view it is dialectal and secondary and the same in the noun (pl. Gr. $\lambda u ́ k o l)$.

Type e), as I have already said, is fundamentally verbal. These are the endings of the type ${ }^{*}-t i$, ${ }^{*}-t o,{ }^{*}-t o i$ : an even more recent variant is *-tor. As is known, they were used to grammaticalize the oppositions of tense and voice. Their origin is not hard to explain: if ${ }^{*_{-}} i$, ${ }_{-}-o$ for example, could be added to $R$, it is clear that the same could be done in a second phase with groups such as $R$-s in which the lengthening did not at first introduce any semantic difference. The $R$-s group became treated as $R$, therefore. All this means that the whole of this type presupposes the establishment of a coupling of verbs or stems, with the consequent development of grammatical categories. As this phenomenon did not occur in the noun (the development of polythematism was restricted to 
the opposition of masculine / feminine and to the degrees of comparison in the adjective), the right circumstances were not created for these terms to arise, neither were they necessary.

Finally, when plurals were created from derived stems (from *domen-, for example, alongside dom-), forms of the *-noi type arose (e. g. Lat. domini), but with no special meaning.

Type f), that of Gr. \& $y \varepsilon i \varsigma$, is clearly dialectal and recent.

With all this, one may see that the origins of the thematic vowel are very old and that it had no semantic value in principle. There was later a formal development partly shared by noun and verb, and partly taken further by this latter. In this, the thematic vowel was still partly a pure formative element without any special meaning, and was partly grammaticalized to express diverse categories, different from those of the noun. The use of short and long forms, with $e$ and $o$ timbres for the purpose of these grammaticalizations, is common to both verb and noun; the same goes for the opposition of thematic and athematic forms. The details of course vary in the way we have explained. Even when there is a common category, that of number, it is expressed as is known in a different way in verb and in noun.

In any case, the desinential use of the thematic vowel - to which we shall return - is not explained completely if one does not consider it in a broader perspective, as likewise the whole of the ${ }_{-}-H_{0},{ }_{-}^{*}(H) o$ inflexion. We shall briefly discuss this subject with a view to bettering the approach according to which there were two verbal inflexions in Indoeuropean, the -mi one and the *-Ho one. Without this being radically false, one should state that it is a simplification which should be corrected.

I mentioned above that I believe that the opposition in Indoeuropean of one - $m i$ inflexion to another ${ }^{*}-H o$ one as forerunner of the Hittite $-m i$ and - $h a$ inflexions, is an over-simplified way of viewing this subject. We have postulated that, alongside ${ }^{*}-\mathrm{Ho}_{0}{ }_{-}{ }_{-} \mathrm{Hto}_{\mathrm{O}}{ }_{-}-(\mathrm{H}) \mathrm{o}$ and with the same meaning, there was ${ }^{*} H,{ }_{-}{ }_{-} H t^{*} *_{-}(H)$ in Indoeuropean. In one and the other inflexion in the oldest phase in which ${ }^{*} H$ is radical, excepting the 2 nd. sing. lengthened with $-t$, there were simply pure ${ }^{*}-H$ stems or else pure ${ }^{*}-H$ stems followed by the thematic vowel. They lacked all tense, voice and mood meaning; the differentiation of these categories, in so far as they existed, was achieved by means of secondary devices: for example, by opposing $-m i$ or $-h i$ to $-b a$ or -hun; -bari to habat. Person was also distinguished by means of a secondary device $(-h i /-i$, $-b a /-a$, by taking advantage of a phonetic process). It is precisely due to these difficulties of the radical forms in marking the categories and 
functions that the -mi inflexion, with its diverse variants, was so successful.

The important thing to point out here, however, is that the existence of stems without endings followed or not by the thematic vowel, is not limited to the ${ }^{*}-H$ and ${ }^{*}-H o$ forms where the ${ }^{*}-H$ was radical (we have mentioned dabbi, tarnabbi and many other examples could be given). This is simply one case among several others. To this effect, the ideas in Adrados 1962: $621 \mathrm{ff}$. should be systematized and brought up to date with the aid of later studies such as Watkins' (1975) on the endings of Baltic, or those of Mme. Bader (1976) on radical forms of *es and other verbs; likewise, the numerous studies on the endings with $-r$, which are becoming more and more widely accepted as old nominal forms (I would say nominal-verbal ones), cf. e. g. Kuryłowicz (1968-69), Bader (1967), Schmidt (1977), Jasanoff (1977), Rosen (1978). These should be contrasted with other interpretations, for example, those of Cowgill (1968). I shall mention here only the most essential points.

Basically, I find radical or thematic forms with $-\varnothing$ endings in the case of roots ending in several consonants or resonants (for example, ${ }^{*} e s,{ }^{*}$ ago / ${ }^{*}$ ago / *age) and in the case of roots in ${ }^{*} e H_{1},{ }^{*}-e H_{2}$ (the Hittite type in - $b a$ and the middle voice and perfect which corresponds to this in other languages are originally a $\emptyset$ degree * ${ }^{*}$ followed by a thematic vowel).

As I have stated before, these forms are found in the three persons of the singular, against which those of the plural represent secondary specializations. They are found moreover in both the indicative and imperative, both being distinguished secondarily and not by the stem but by means of secondary elements in the inflexion. Furthermore, there are traces of an older non-differentiation of indicative/subjunctive: sometimes there are common forms which are distinguished secondarily, cf. e. g. O. I. bhárāmi / bhárāni from an older bháră, cf. Gr. ind.-subj. $\phi \varepsilon \rho \omega$ and Adrados 1973: 721. The non-differentiation of indicative/ imperative is kept for example in Gr. $\varepsilon$. In Baltic above all we find the old non-differentiation of present/preterite kept, which we had already deduced from the double use of - ba in Anatolian.

Thus, in fact, we find the recently mentioned types *es and *ag $\delta$ / *ago / *age and, together with other rare ones, also types in *-e and *-a, which frequently alternate with the variants $*_{-}-\bar{e} u$ and $*_{-}^{-a} u$ : according to our phonetic theory (Adrados 1961: $338 \mathrm{ff}$., among other instances) these are phonetic variants originally conditioned by the context; otherwise, they would be *-u lengthenings. These forms, as we have stated, are found in the three persons of the singular and in the different tenses, 
moods and voices: it is clear that athematic and thematic radical forms did not participate in the origin of these categories, which are more recent. The meaning of each form was only established within the systems of oppositions which were created.

Thus, for example, when the radical or thematic form is opposed to one from the regular ending system: we have already seen the passage

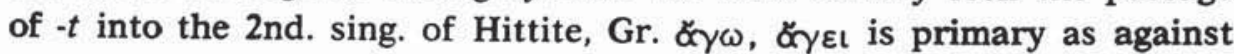
an imperfect with $-m,-s,-t$, Hitt. -ba is preterite as against $-m i$, $-b i$, etc. In other instances, these regular endings or other elements are added to a given form: thus in $\mathbf{O}$. I. bhárāmi (Ind.) as against a different subjunctive as I have just said. These "other elements» are generally lengthenings, above all $-i$, which makes forms such as dabbi, $\mathrm{O}$. I. bháve,

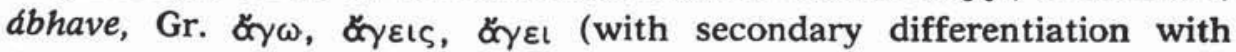
desinential $-s$ and opposed to the imperative) present ones. Cf. interesting material on this $-i$, which nevetheless does not derive at all from the imperative, in Mme. Bader (1976) and in Negri (1974). It is worth noting, for example, how *es-i became 2nd. sing. as from Indoeuropean, by means of an opposition to forms with regular endings. There are of course other endings and lengthenings, above all $-r$, the forms of the imperative, etc. Another example is that as against O. I. jajñă / jajñau, Lat. has gnōui, with *-ai: the old perfect form has been added to a pure stem; of course the same ${ }^{*}-\bar{a} u$ - at times spread as a lengthening. Thus also in Tocharian, in the B dialect of which there is 1st. sing. pres. $-a u$ (also turned into an ending) and 1st. sing. pret. $-\bar{a},-\bar{a} w \bar{a},-\bar{a} w a$, the distinction thus being made. This is not the case in Baltic in which the endings of present and preterite are identical in thematic and athematic forms: the distinction is made by the stem. But it was necessary to distinguish persons: therefore devices such as those mentioned above were resorted to, for example, by using in certain stems 1st. -au, 3rd. -o (phonetic difference), 2nd. -ai (lengthening).

Sometimes one of these devices was widespread, thus the $-\bar{o}$ of the 1st. sing. or the primary $-i$ (which for the rest may be missing: precisely here). Others never became established in categories of forms except at a dialectal level or that of each language. We have seen how the thematic vowel occurs sometimes in the active and sometimes in the middle voice, how it is used with both $-e$ and $-o$ timbres. The final * $-\bar{a}$, and ${ }^{*}-\bar{a} u, *^{*} \bar{e}$ and ${ }^{*} \cdot \bar{e} u$ are used in several tenses and moods in very varied distributions. One may add to the examples given above, among many others, those which are to be deduced by taking away the final $-r$ of certain forms, cf. e. g. Lat. dica-r, amaba-r, O. Ir. -bera-r (1st. 3rd. subj.), etc. 
We once more get a view of the oldest type of Indoeuropean, preserved here and there at times, in which certain forms were modified, or were simply opposed to others in order to mark the new categories and functions. As one form intervenes in several of these oppositions, it is clear that it could mean several categories, that is that there are what we call amalgams. The $-\bar{o}$ of $\mathrm{Gr}$. $\not \alpha \gamma \omega$ indicates person, voice, mood and tense, for example; and the same form marks different things in different languages, according to the oppositions in which it is included. As we have already said, it even marks two different categories at the same time (syncretisms such as that of Gr. indicative-subjunctive $\phi \varepsilon \varepsilon^{\prime} \omega$ ).

It is therefore an erroneous conception to claim that there were always 1:1 rations in the oldest form of Indoeuropean, that is, that each morpheme marked one category and vice-versa. On the contrary, we have discovered proportionally defined markers and others which are not even defined as regards oppositions such as those of person, mood, tense, voice, or else are defined secondarily. Only the context dispelled ambiguity. I do not therefore believe that Cowgill is right (1968) when he explains amalgams such as those mentioned here, by means of the fusion or contraction of older independent markers: the Italo-Celtic -or would come from *-o-H-o-r, the thematic subjunctive of 0 . I. $-\bar{a} i$ would come from *-o-o-H-o-y. This is the opposite point of view to that which I have upheld, by which I explain all processes of grammaticalization in their different chronology and dialectal diffusion and draw attention to the remains of non-differentiation of certain elements with respect to later categories.

Finally, one more argument in favour of the old non-differentiation of the thematic vowel with respect to voice, which is what most concerns us, is that not only do forms such as *-so appear without any voice meaning of their own (in deponents or otherwise) in the languages which developed opposition of voices, but also in other languages which, we believe, did not achieve this. Thus, Slavonic, above all, in which forms equivalent to those of the active and middle voice of other languages are mixed in a paradigm. Contrary to widespread opinion I still believe (cf. Adrados 1963: 647) that there really is a continuation here of an old non-differentiation: of what occurred in other languages with the activa tantum and the deponents. The same occurs in the case of Armenian, of Baltic (cf. the thesis of fusion in K. H. Schmidt), of the Celtic imperfect (cf. the data in Hollifield 1978: $218 \mathrm{ff}$.), of Gothic stems without voice opposition. On voice in Germanic cf. recently R. Lühr (1978). In fact, the creation of the active/middle voice opposition goes back to an early date, that of IE II, but it took a long time to be com- 
pleted. Cf. on its secondary origin, the ideas of W. R. Schmalstieg (1977). The large number of activa tantum and deponents which, on a purely lexical basis, kept up the old non-differentiation of voice and even the lack of voice opposition in some languages, bears witness to this. It is one more proof that not even the perfect was originally a middle voice form, neither was the stative, the basis of the middle voice and the perfect.

I believe that in this way the creation of the middle voice and the perfect fits into the creative process of Indoeuropean morphology. A series of successive oppositions gave their meanings to the formal markers, the thematic vowel included, and to the categories and functions which were created. Moreover, in this way, the creation of the middle voice and the perfect is a parallel in general, if not in specific, terms to the process which created the rest of the oppositions of temporal, modal and aspectual stems.

Francisco R. Adrados

\section{BIBLIOGRAPHY}

Adrados, F. R.

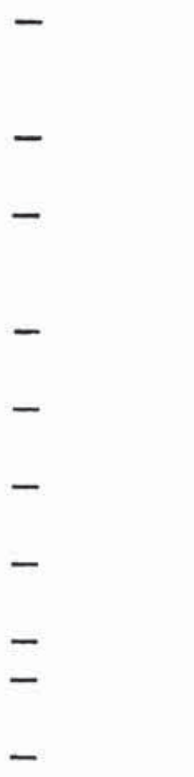

(1961): Estudios sobre las laringales indoeuropeas, Madrid, C. S. I. C. (2nd ed. 1973, Estudios sobre las sonantes $y$ laringales indoeuropeas).

(1962): «Hethitisch und Indogermanisch», in Fachtagung für indogermanische und allgemeine Sprachwissenschaft (1961). Innsbruck, pp. 145-151.

(1963): Evolución y estructura del verbo indoeuropeo, Madrid, C. S. I. C. 2nd enlarged ed. 1974.

(1965): *Historische und strukturelle Methode in der indogermanischen Sprachwissenschaft», Kratylos 10, pp. 131154.

(1968): «Die Rekonstruktion des Indogermanischen und die strukturalistische Sprachwissenschaft», IF 73, pp. 1-47.

(1970): «Das Hethitische und die idg. Laryngale», RHA 28, 1970, pp. 7-17.

(1971): «On indoeuropean sigmatic verbal stems», Archivum Linguisticum 2, pp. 95-116.

(1972): «Hethitische Endungen und Indogermanisches Verb», Folia Linguistica 5, pp. 366-381.

(1975): Lingüistica Indoeuropea, Madrid, Gredos.

(1979): «Arqueología y diferenciación del Indoeuropeo», Emerita 47 , pp. 261-282.

(forth. 1): «The archaic structure of Hittite: the crux of the problem». 
Adrados, F. R. (forth. 2): «Indoeuropean $-s$ stems and the origins of poly thematic verbal inflexion

(forth. 3): «Further considerations on the Phonetics and Morphologizations of $\mathrm{H}^{\mathrm{i}}$ and $\mathrm{H}_{\mathrm{u}}$.

Ambrosini, $\mathbf{R}$.

(forth.4): «More on the laryngeals with labial and palatal appendixes».

(1962): «Concordanze della Struttura formale delle categorie verbali Indo-Europee, in Studi e Saggi Linguistici 2, pp. 33-97.

Bader, F.

(1967): «Le système des désinences de troisième personne du pluriel du perfectum latin», BSL 62, pp. 87-105.

(1972): «Parfait et Moyen en Grec» in Mélanges Chantraine, pp. 1-21. Paris, Klincksieck.

(1974): «Persée, et l'expression archaïque du temps en indoeuropéen», BSL 69, pp. 1-53.

(1975): «La structure thématique aux presents hittites», RHA 33, pp. 5-29.

(1976): «Le present du verbe 'être' in indoeuropéen», $B S L$, pp. 27-111.

(1978): «Flexions d'aoristes sigmatiques», in Etrennes de Septantaine, Paris, Klincksieck, pp. 29-44.

Beekes, R. S. P. (1973): «The Protero-dynamic Perfekt», KZ 87, pp. 86-98.

-

Bernabé, A.

van Brock, N.

Carruba, $\mathbf{0}$.

Cowgill, w.

Eichner, $\mathrm{H}$.

Georgiev, V.

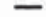

Gonzálezz Fernández, J. (1980):

Jasanoff, J. H. (1979): Tectum y el testimonio del verbo hitita», Emerita 48.

(1974): «Old Hittite 1 sg. -he: 3 sg. i», KZ 88, pp. 72-76.

(1973): «Geminación de $s$ y sonantes en hetita», RSEL 3, pp. 415-456.

(1964): «Les thèmes verbaux à redoublement du hittite et le verbe indoeuropéen», RHA 22, pp. 119-165.

(1976): «Anatolico e Indoeuropeo», in Scritti Bonfante I, pp. 121-146, Brescia, Paideia.

(1968): *The first person singular medio-passive of indo iranian», in Pratidänam, pp. 24-31. La Haya, Mouton.

(1975): «More Evidence for Indo-Hittite: the Tense-Aspect Systemsw, in Proceedings of the Eleventh Internatio nal Congress of Linguists II, pp. 557-570. Bolonia, II Mulino.

(1979): «Anatolian hi-Conjugation and Indo-European Perfect: Instalment IIx, in Hethitisch und Indogermanisch, pp. 25-39. Innsbruck.

(1975): «Die Etymologie von heth. mehur», MSS 31, pp. 68-69.

(1975): «Die Entstehung der indoeuropäischen Verbal-Kategorien», Balk. E. 18, pp. 5-56.

1978): «Morphologische Untersuchungen, I. Probleme der ide. Verbalflexion», Ling. Balk. 21, pp. 5-34.

«El carácter temporal de la oposición infectum/perund Indogermanisch, pp. 79-90. Innsbruck.

Kerns, J. A. and Schwarz, B.
(1972): A Sketch of the indo-european finite Verb., Leiden, Brill. 
Kuryłowicz, J. (1932): «Les désinences moyennes de l'Indoeuropéen et du hittite», BSL 33, pp. $1-4$.

(1964): The inflectional Categories of Indo-European, Heidelberg.

(1968/69): «La désinence verbale $-r$ en indo-européen et en celtique», EC 12, pp. 7-20.

(1975): Esquisses Linguistiques II. Munich, Fink, pp. 447-453: «Das idg. Perfekt im Slavischen», pp. 475-479: «Les itératifs en -eie/o en slave et en baltiquex.

(1977): Problèmes de Linguistique indo-européenne. Wroklaw, Academy of Sciences.

(1979): «Die Hethitische -hi-Konjugation», in Hethitisch und Indogermanisch, pp. 143-146. Wiesbaden, Reichert.

Lehmann, W. P. (1974): Protoindoeuropean Syntax. Austin-Londres.

Lühr, R.

Meid, W.

(1978): «Die Kontinuante der urindogermanischen Medialflexion im Germanischen», MSS 37, pp. 109-130.

(1971): Das germanische Praeteritum. Indogermanische Grundlagen und Ausbreitung im Germanischen. Innsbruck.

(1975): «Räumliche und zeitliche Gliederung des Indogermanischen, in Flexion und Wortbildung, pp. 204-219. Wiesbaden. Reichert.

(1979): «Der Archaismus des Hethitischen», in Hethitisch und Indogermanisch. Innsbruck.

Narten, J.

(1968): «Zum proterodynamischen Wurzelpresent», in Pratidānam, pp. 9-19. La Haya, Mouton.

Negri, M.

Neu, $\mathbf{F}$.

Oettinger, $\mathrm{N}$.

Puhvel, J.

Risch, F.

(1974): «Studi sul verbo greco», Acme 27, pp. 359-379.

(1968): Das Hethitische Mediopassiv und seine indogermanischen Grundlagen. Wiesbaden, Harrassowitz.

(1976): «Der indogermanische Stativ», MSS 34, pp. 109-149.

(1970): «Perfect Tense and Middle Voice. An Indo-European Morphological Mirage», in Proceedings of the Tenth International Congress of Linguists IV, pp. 629-34. Bucarest.

(1975): «Zur Entstehung des Hethitischen Verbalparadigmas», in Flexion und Wortbildung, pp. 247-258. Wiesbaden, Reichert.

Rix, H.

(1977): «Das keltische Verbalsystem auf dem Hintergrund des indoiranisch-griechischen Rekonstruktionsmodell», in Indogermanisch und Keltisch, pp. 132-158. Wiesbaden, Reichert.

Rosen, H. B.

(1978): «Amamini und die idg. Diathesen und Valenzkategorien», KZ 92, pp. 143-178.

Rosenkranz, B. (1968): «Die Hethitische -hi-Konjugation und das indogermanische Perfektum», KZ 75, p. 215.

(1979): *Archaismus in Hethitischen», in Hethitisch und indogermanisch, pp. 219-229. Innsbruck.

Schmalstieg, W. R. (1977): *Speculations on the Indo-European Active and Middle Voices», KZ 90, pp. 23-36. 
Schmalstieg, W. R. (1977 bis): «A note on the verbal Person Markers in Indoeuropean», $K Z$ 90, pp. 72-76.

Schmid, W. P.

(1979): «Das Hethitische in einem neuen Verwandtschaftsmodell», in Hethitisch und Indogermanisch, pp. 231-235. Innsbruck.

Schmidt, G.

(1977): «Das Medium in vorhistorischen Keltisch», in Indogermanisch und Keltisch, pp. 89-107. Wiesbaden, Reichert.

Schmidt, $K$.

(1975): «Die Gebrauchweisen des Mediums in Tocharischen», IF 80 , pp. $230-232$.

Schmidt, K. H.

(1970): Zum Typus der baltischen Personalflexion», in Donum Balticum, Estocolmo, 1970, pp. $480-484$.

Stang, Chr.

Watkins, W.

(1932): «Perfektum und Medium», NTS 6, pp. 29-39.

(1969): Indogermanische Grammatik, Band III. Formentehre. Heidelberg, Winter.

(1970): «Remarks on Baltic Verb Inflexion», in Baltic Linguistics, pp. 165-170. University of Pennsylvania.

(1971): «Hittite and Indo-European studies: the denominative statives in - $\bar{e}_{\star}, T P H S$, pp. $51-93$.

(1975): «Vertretung der Laryngale in den idg. Sprachen Anatoliens», in Flexion und Wortbildung, pp. 358-378. Wiesbaden, MSS 31, pp. 68-69. Reichert. 